\title{
MELHORAMENTO DO TRIGO: XXVI. AVALIAÇÃO DE LINHAGENS COM TOLERÂNCIA À TOXICIDADE DE ALUMÍNIO, MANGANÊS E FERRO EM SOLUÇÕES NUTRITIVAS $\left({ }^{1}\right)$
}

\author{
CARLOS EDUARDO DE OLIVEIRA CAMARGO $\left({ }^{2,3}\right)$, LAÉRCIO SOARES ROCHA \\ JÚNIOR ${ }^{2}$ ) e ANTONIO WILSON PENTEADO FERREIRA FILHO $(2,3)$
}

\begin{abstract}
RESUMO
Efetuaram-se cruzamentos entre o cultivar $\mathrm{BH}-1146$, de porte alto, tolerante à toxicidade de alumínio e sensível à toxicidade de ferro e manganês, e o cultivar Siete Cerros, de porte semi-anão, sensível à toxicidade de alumínio, porém com tolerância à toxicidade de ferro e manganês. Selecionaram-se plântulas desse cruzamento, em geração $F_{2}$, quanto à tolerância ao alumínio (10mg/litro), empregando-se soluçőes nutritivas, e plantaram-nas em vasos no telado contra o ataque de pássaros. A partir da geração $F_{3}$ até $F_{6}$, selecionaram-se plântulas em soluçōes nutritivas distintas contendo $6 \mathrm{mg} /$ litro de $\mathrm{A}^{3+}, 600 \mathrm{mg} /$ litro de $\mathrm{Mn}^{2+}$ e $10 \mathrm{mg} /$ itro de $\mathrm{Fe}^{2+}$. Avaliaram-se as vinte e três linhagens obtidas - doze de porte semi-anão e onze de porte alto juntamente com os cultivares BH-1146 e Siete Cerros em três experimentos, empregando-se soluções nutritivas. No primeiro, utilizaram-se os níveis de $0,2,4,6,8$ e $10 \mathrm{mg} /$ litro de $\mathrm{Al}^{3+}$; no segundo, 0,$11 ; 300 ; 600$ e $1.200 \mathrm{mg} /$ itro de $\mathrm{Mn}^{2+}$ e no terceiro, 0,$56 ; 5 ; 10$ e $20 \mathrm{mg} /$ /itro de $\mathrm{Fe}^{2+}$. Os resultados obtidos permitiram confirmar que as vinte e três linhagens selecionadas apresentaram, ao mesmo tempo, tolerância à toxicidade de $\mathrm{Al}^{3+}, \mathrm{Mn}^{2+}$ e $\mathrm{Fe}^{2+}$.
\end{abstract}

Termos de indexação: trigo, linhagens, cultivares, comprimento da raiz, toxicidade de alumínio, manganês e ferro, tolerância, sensibilidade.

\section{ABSTRACT \\ WHEAT BREEDING: XXVI. EVALUATION OF INBRED LINES WITH TOLERANCE TO ALUMINUM, MANGANESE AND IRON TOXICITIES IN NUTRIENT SOLUTIONS}

Crosses were made between $\mathrm{BH}-1146$, a tall wheat standard cultivar and tolerant to toxic effects of aluminum and sensitive to iron and manganese excessive levels, and Siete Cerros, a semidwarf cultivar and sensitive to aluminum and tolerant to iron and manganese toxic effects. Seedlings of this cross, in $F_{2}$ generation, were selected

(') Com verba suplementar do Acordo do Trigo entre as Cooperativas de Produtores Rurais do Vale do Paranapanema e a Secretaria de Agricultura e Abastecimento, através do Instituto Agronómico. Trabalho apresentado no "Second International Symposium Plant-Soil Interactions at Low pH", em Beckley, West Virginia (EUA), em junho de 1990, e na XVI Reuniäo Nacional de Pesquisa de trigo, Dourados (MS), em julho de 1991. Recebido para publicação em 18 de janeiro de 1991 e aceito em 8 de janeiro de 1992.

(2) Seção de Arroz e Cereais de Inverno, Instituto Agronômico (IAC), Caixa Postal 28, 13001 Campinas, SP.

(3) Com bolsa de pesquisa do CNPq. 
for aluminum tolerance (10 $\mathrm{mg} / \mathrm{l})$ using nutrient solutions. Tolerant plants were transplanted to pots into a screenhouse. Selections of tolerant plants for aluminum, iron and manganese were made from $F_{3}$ to $F_{6}$ generations using distinct nutrient solutions with $6 \mathrm{mg} / \mathrm{l}$ of $\mathrm{Al}^{3+}, 600 \mathrm{mg} / \mathrm{l}$ of $\mathrm{Mn}^{2+}$ and $10 \mathrm{mg} / \mathrm{l}$ of $\mathrm{Fe}^{2+}$. Twenty three inbred lines were obtained and evaluated with the cultivars BH-1146 and Siete Cerros in three experiments, using nutrient solutions. In the first experiment, the following levels of $A^{3+}$ were used: $0,2,4,6,8$ and $10 \mathrm{mg} /$; in the second experiment, the following levels of $\mathrm{Mn}^{2+}$ were used: $0.11 ; 300 ; 600$ and $1,200 \mathrm{mg} /$; and in the third experiment, $\mathrm{Fe}^{2+}$ was used at: $0.56 ; 5 ; 10$ and $20 \mathrm{mg} /$. The results permitted to confirm that selected inbred lines presented simultaneous tolerance to aluminum, manganese and iron toxicities.

Index terms: wheat, inbred lines, cultivars, root length, aluminum, manganese and iron toxicities, tolerance, sensitivity.

\section{INTRODUÇÃO}

Grandes áreas dos solos brasileiros são ácidas. Tais solos contêm alumínio solúvel ou trocável que inibem o crescimento das raízes da maioria das variedades de trigo, resultando em reduzido perfilhamento e baixa produtividade.

CAMARGO (1981) demonstrou que a tolerância do trigo 'BH-1146' se deve a um par de genes dominantes em cruzamentos desse cultivar com os cultivares sensíveis Tordo e Siete Cerros, empregando concentrações de $3 \mathrm{mg} /$ /itro de $\mathrm{Al}^{3+}$ em soluções nutritivas. Posteriormente, LAGOS et al. (1984), estudando plantas monossômicas $(2 n=41)$ de linhas aneuplóides e normais $(2 n=42)$ do genótipo Chinese Spring, identificadas citologicamente, as quais foram cruzadas com o $\mathrm{BH}-1146$, concluíram que o gene de tolerância ao $\mathrm{Al}^{3+}$ nesse cultivar está localizado no cromossomo 4D.

CAMARGO et al. (1980) concluíram que a tolerância ao alumínio apresentou alto valor de herdabilidade em sentido restrito, sugerindo que a seleção para plantas tolerantes em uma população segregante seria eficiente nas primeiras gerações.

Os sintomas de toxicidade de manganês nas plantas são mais pronunciados nas folhas do que nas raízes, embora haja variação bastante acentuada entre as espécies cultivadas (ANDREW \& PIETERS, 1970). Em casos de severa toxicidade, as raízes tornam-se de coloração castanha, mas este sintoma geralmente ocorre quando a parte aérea já está bastante injuriada (FOY et al., 1978). Isso contrasta com o efeito do alumínio, que reduz fortemente o crescimento das ralzes, sem produzir sintomas facilmente identificáveis na parte aérea (FOY et al., 1978).

Alguns solos não produzem efeitos tóxicos de manganês em plantas sensíveis, mesmo em pH 5,0 ou inferior, porque suas rochas-mães contêm baixo teor de manganês em sua constituição; logo, tais solos seriam indicados para o estudo da tolerância ao alumínio, que, por outro lado, é um dos constituintes das partículas de argila do solo, sendo, portanto, seu efeito tóxico teoricamente possível em qualquer solo, dependendo do pH (FOY, 1976). 
CAMARGO (1983, 1988) e CAMARGO \& OLIVEIRA (1983) estudaram as gerações $F_{1}$ e $F_{2}$ de um cruzamento entre os cultivares Siete Cerros e BH-1146, tolerante e sensivel, respectivamente, à toxicidade de manganês. A tolerância à toxicidade de alumínio e de manganês foi oposta nos dois cultivares. Informações semelhantes foram obtidas com o 'Atlas-66' (tolerante ao alumínio e sensivel ao manganês) e 'Monon' (sensível ao alumínio e tolerante ao manganês) em estudos feitos por FOY et al. (1973). Tais fatos demonstram que a tolerância a esses dois estresses, observados em solos ácidos, são geneticamente independentes e que a seleção num programa de melhoramento para um caráter não significa seleção simultânea para o outro. CAMARGO (1983) encontrou valor elevado para a herdabilidade em sentido amplo para a tolerância ao manganês e concluiu que a seleção para essa tolerância também seria efetiva nas primeiras gerações após o cruzamento.

Nos últimos anos, a toxicidade de ferro tem constituldo um problema sério na cultura do trigo no Estado de São Paulo, seja em condições de sequeiro, seja de irrigação por aspersão, provocando um amarelecimento acentuado nas folhas inferiores das plantas. Esses sintomas ficam evidenciados nos anos chuvosos, em cultura de sequeiro, enquanto são mais freqüentes em condições de irrigação, em decorrência do aparecimento de uma camada de adensamento no solo na profundidade de $20-30 \mathrm{~cm}$.

Verificou-se que os genes existentes no cultivar Siete Cerros, responsáveis pela tolerância a $10 \mathrm{mg} /$ ittro de $\mathrm{Fe}^{2+}$ nas soluções, apresentaram comportamento parcialmente dominante, e os genes encontrados no 'BH-1146', comportamento parcialmente recessivo. Os valores da herdabilidade em sentido amplo para a tolerância à toxicidade de $\mathrm{Fe}^{2+}$, expressa na capacidade de crescimento das ralzes das plântulas de trigo em soluções nutritivas contendo 5 e $10 \mathrm{mg} /$ itro de $\mathrm{Fe}^{2+}$, foram altos, indicando que grande parte da variabilidade da população $\mathrm{BH}-1146 \times$ Siete Cerros, em geração $F_{2}$, foi de origem genética, permitindo, pois, seleções nas primeiras gerações segregantes para essa característica (CAMARGO, 1985).

O presente trabalho tem por objetivo avaliar, em soluções nutritivas, linhagens de trigo provenientes do cruzamento $\mathrm{BH}-1146 \times$ Siete Cerros quanto à tolerância à toxicidade de $\mathrm{Al}^{3+}, \mathrm{Mn}^{2+}$ e $\mathrm{Fe}^{2+}$.

\section{MATERIAL E MÉTODOS}

\subsection{Origem dos genotipos estudados}

Foram estudadas 23 linhagens em geração $F_{6}$ provenientes do cruzamento entre os cultivares $\mathrm{BH}-1146$, de porte alto, tolerante à toxicidade de $\mathrm{Al}^{3+}$ e sensivel à de $\mathrm{Mn}^{2+}$ e $\mathrm{Fe}^{2+}$, e o Siete Cerros, de porte semi-anão, sensível à toxicidade de $\mathrm{Al}^{3+}$, porém tolerante à de $\mathrm{Mn}^{2+}$ e $\mathrm{Fe}^{2+}$ 
Plântulas em geração $F_{2}$ desse cruzamento foram avaliadas quanto à tolerância à toxicidade de $\mathrm{Al}^{3+}$, empregando-se soluções nutritivas contendo 10 $\mathrm{mg} /$ itro de $\mathrm{Al}^{3+}$, segundo o método descrito por CAMARGO $(1981,1984)$. Em virtude da existência de grande disponibilidade de plântulas em geração $F_{2}$, de acordo com CAMARGO (1984) seria mais interessante selecioná-las em altas concentrações de $\mathrm{Al}^{3+}$ (10mg/litro) na solução, pois seriam eliminadas as plantas sensiveis (homozigotas recessivas e heterozigotas) e selecionadas as tolerantes homozigotas.

As plântulas tolerantes foram transplantadas para vasos de plástico preto, com $20 \mathrm{~cm}$ de altura por $20 \mathrm{~cm}$ de diâmetro, preenchidos com solo calcariado e adubado, localizados no telado contra o ataque de pássaros, no Centro Experimental de Campinas. As plântulas desenvolveram-se nessas condições, recebendo irrigação diária até a época de maturação.

As plantas foram colhidas individualmente e as sementes de cada planta, divididas em três partes.

Na geração seguinte $\left(F_{3}\right)$, a primeira parte das sementes de cada planta foi posta a germinar, sendo as plântulas originárias avaliadas em soluções contendo $6 \mathrm{mg} / \mathrm{litro}$ de $\mathrm{Al}^{3+}$. A segunda e a terceira parte das sementes de cada planta que teve sua descendência $100 \%$ tolerante ao $\mathrm{Al}^{3+}$, isto é, estavam homozigotas para essa característica, foram testadas em soluções com $600 \mathrm{mg} /$ itro de $\mathrm{Mn}^{2+}$ e $10 \mathrm{mg} /$ /itro de $\mathrm{Fe}^{2+}$ respectivamente. As plântulas emergentes que exibiram maior tolerância ao $\mathrm{Mn}^{2+}$ e ao $\mathrm{Fe}^{2+}$, concomitantemente, foram selecionadas e transplantadas para vasos onde permaneceram até a época da maturação, nas condições mencionadas.

Esse procedimento foi seguido até a geração $F_{6}$, onde foram selecionadas as linhagens de 1 a 12. de porte semi-anão e de 13 a 23 de porte alto, as quais foram estudadas em soluções nutritivas contendo diferentes niveis de $\mathrm{Al}^{3+}, \mathrm{Mn}^{2+} \mathrm{eFe}^{2+}$, visando confirmar a tolerância genética aos três tipos de toxicidade considerados.

Os cultivares de trigo $\mathrm{BH}-1146$ e Siete Cerros foram utilizados como controles. $\mathrm{O}$ 'BH-1146', selecionado no Instituto Agronômico de Minas Gerais, Belo Horizonte, é proveniente do cruzamento 'Ponta Grossa l' x 'Fronteira', hibrido que foi cruzado com o cultivar Mentana. $O$ 'Siete Cerros' foi introduzido do Centro Internacional de Melhoramento de Milho e Trigo (CIMMYT), México, sendo procedente do cruzamento Penjamo 62/Gabo 55.

\subsection{Avaliação dos genótipos quanto à tolerância à toxicidade de $\mathrm{Al}^{3+}$}

As plântulas das linhagens e dos cultivares foram testadas em condições de laboratório, para tolerância a $0,2,4,6,8$ e $10 \mathrm{mg} /$ itro de $\mathrm{Al}^{3+}$ em soluções nutritivas, conforme MOORE et al. (1976), CAMARGO et al. (1980) e CAMARGO \& OLIVEIRA (1981). O delineamento estatístico empregado foi de blocos ao acaso com parcelas 
subdivididas, sendo as parcelas compostas por seis concentrações de alumínio e, as subparcelas, pelos genótipos de trigo. Efetuaram-se quatro repetições para cada solução de tratamento. Os dados foram avaliados, considerando-se a média de comprimento da raiz primária central das dez plântulas de cada genótipo, em 72 horas de crescimento nas soluções nutritivas completas sem alumínio, que se seguiu a 48 horas de crescimento nas soluções de tratamento contendo seis diferentes concentrações de alumínio.

Realizou-se a análise da variância para cada concentração de alumínio, com o objetivo de verificar o efeito de genótipos (23 linhagens e o ' $\mathrm{BH}-1146$ '), sendo a comparação entre as linhagens e o cultivar (testemunha tolerante ao alumínio), dentro de cada concentração de alumínio, feita pelo teste de Dunnett unilateral, ao nível de 5\% (STEEL \& TORRIE, 1960).

\subsection{Avaliação dos genótipos quanto à tolerância à toxicidade de manganés e ferro}

As plântulas das linhagens e dos dois cultivares controles foram testadas em condição de laboratório em dois experimentos: no primeiro, para tolerância a 0,11; $300 ; 600$ e $1.200 \mathrm{mg} /$ litro de $\mathrm{Mn}^{2+}$ em soluções nutritivas, conforme método de CAMARGO (1983), e CAMARGO \& OLIVEIRA (1983), e no segundo, para tolerância a 0,$56 ; 5,0 ; 10,0$ e 20,0mg/litro de $\mathrm{Fe}^{2+}$ em soluções nutritivas, conforme CAMARGO \& FREITAS (1985); CAMARGO (1988), e CAMARGO et al. (1989). O delineamento estatístico utilizado nos dois ensaios foi o de blocos ao acaso com parcelas subdivididas, sendo as parcelas compostas pelas quatro concentrações de manganês ou ferro, conforme o experimento e, as subparcelas, pelos genótipos de trigo. Foram feitas quatro repetições para cada um dos experimentos.

Os dados de crescimento das raízes foram obtidos, considerando-se a média do crescimento das raízes das dez plântulas de cada genótipo, em cada repetição de cada experimento, após permanência durante doze dias nas diferentes soluções.

Foi feita análise da variância de cada experimento para verificar o efeito de concentração de $\mathrm{Mn}^{2+}$ ou $\mathrm{Fe}^{2+}$, genótipos e interação genótipos $x$ concentrações de $\mathrm{Mn}^{2+}$ ou $\mathrm{Fe}^{2+}$, e calculados os parâmetros das equações de regressão linear e os coeficientes de determinação para cada genótipo, levando-se em consideração o comprimento médio das raízes em função da concentração de manganês e ferro nas soluções nutritivas.

\section{RESULTADOS E DISCUSSÃO}

O comprimento médio das raízes das 23 linhagens e do ' $\mathrm{BH}-1146$ ', medido após 72 horas de crescimento nas soluções nutritivas completas e depois de $\mathbf{4 8}$ horas de crescimento nas soluções de tratamento contendo seis diferentes concentrações de alumínio $(0,2,4,6,8$ e 10mg/litro) encontram-se no quadro 1 . 


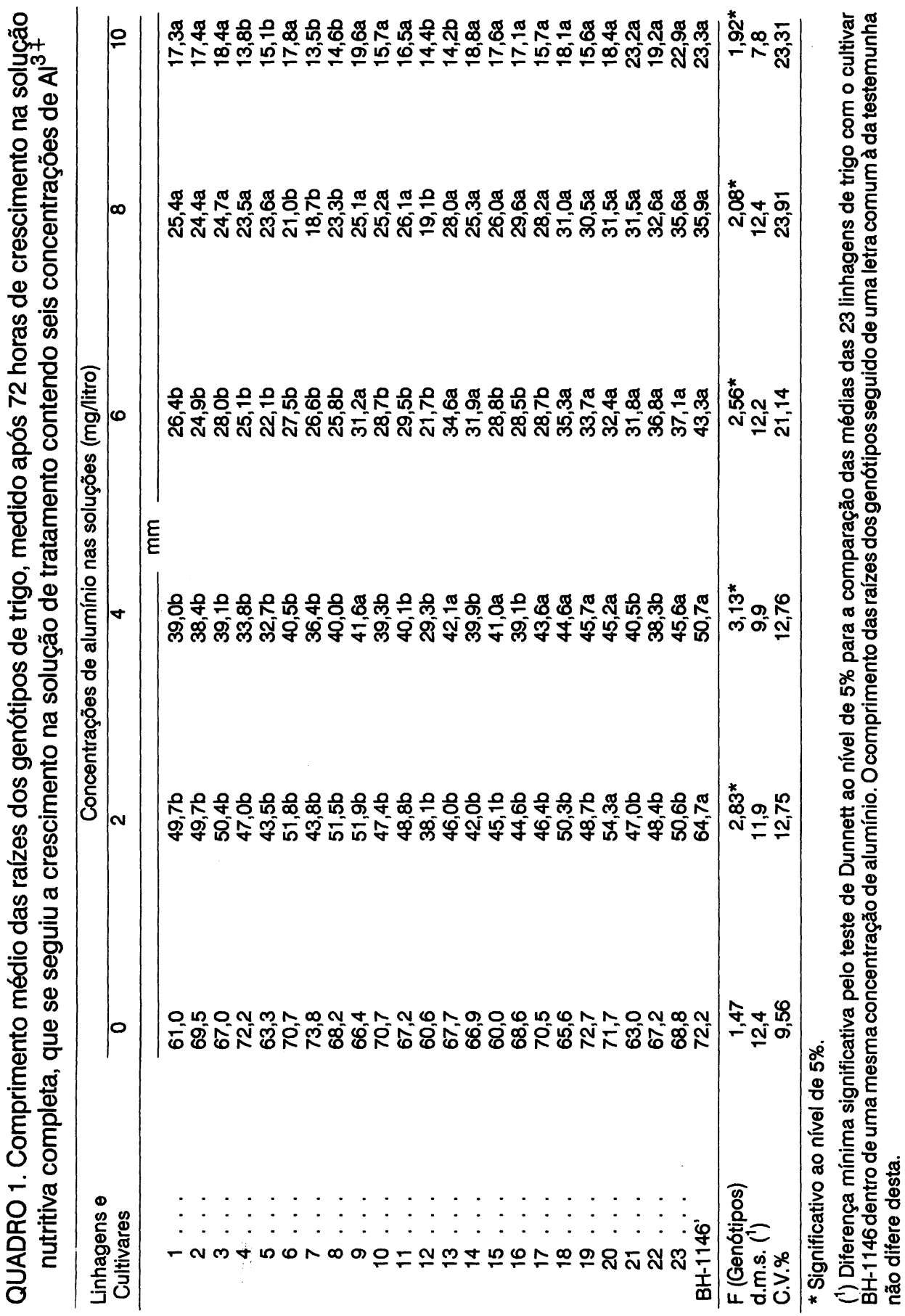


Considerando-se as médias dos diferentes genótipos estudados em soluções de tratamento com ausência de $\mathrm{Al}^{3+}$, verifica-se que as linhagens não diferiram do cultivar $\mathrm{BH}-1146$ pelo teste de Dunnett unilateral, ao nivel de $5 \%$. Essas observações confirmam resultados de CAMARGO \& OLIVEIRA (1981) e CAMARGO et al. (1988): em uma solução com níveis adequados de nutrientes, na ausência de alumínio, com pH 4,0, o 'BH-1146' apresentou o seu potencial genético no crescimento rápido das raízes, condição essa específica de cada genótipo.

Nas soluções de tratamento contendo $\mathrm{Al}^{3+}$, todos os genótipos reduziram o crescimento radicular em relação ao apresentado nas soluções de tratamento contendo $0 \mathrm{mg} /$ litro de $\mathrm{Al}^{3+}$.

O cultivar Siete Cerros foi totalmente sensível a partir de $2 \mathrm{mg} /$ /itro de $\mathrm{Al}^{3+}$, isto é, exibiu paralisação irreversível no crescimento das raízes após permanecer 48 horas nas soluções com essa concentração de alumínio. Nessas condições, 0 ' $\mathrm{BH}-1146$ ' e as 23 linhagens oriundas de seleção do híbrido 'BH-1146' $x$ 'Siete Cerros' apresentaram crescimento radicular, sendo, portanto, considerados tolerantes à toxicidade de $\mathrm{Al}^{3+}$.

Apesar de $\mathrm{O}$ ' $\mathrm{BH}-1146$ ' e de todas essas linhagens serem consideradas tolerantes à toxicidade de alumínio, por exibirem crescimento radicular após serem submetidas a crescimento em soluções nutritivas contendo diferentes concentrações de $\mathrm{Al}^{3+}$, verificou-se em todas as concentrações de $\mathrm{Al}^{3+}$ (2 a 10mg/litro) que o cultivar $\mathrm{BH}-1146$ mostrou o maior crescimento radicular, sendo, portanto, considerado o genótipo mais tolerante. A linhagem 20, não diferindo do cultivar $\mathrm{BH}-1146$ pelo teste de Dunnett unilateral, ao nível de $5 \%$, em crescimento radicular nas concentrações de $2,4,6,8 \mathrm{e} 10 \mathrm{mg} /{\text { litro de } \mathrm{Al}^{3+}}^{3+}$, pode ser considerada como muito tolerante. As linhagens 9,18 e 19 podem também ser consideradas como de elevado nível de tolerância, por não diferirem do cultivar $\mathrm{BH}-1146$ em relação ao crescimento radicular nas concentrações de 4, 6, 8 e $10 \mathrm{mg} / \mathrm{litro}$ de $\mathrm{Al}^{3+}$. As linhagens $4,5,7,8$ e 12 foram as menos tolerantes, por apresentarem raízes significativamente menores em relação ao ' $\mathrm{BH}-1146$ ' em, pelo menos, três das concentrações de $\mathrm{Al}^{3+}$ (2 a 10mg/litro).

A análise da variância para crescimento das raízes de 25 genótipos de trigo estudados em um experimento contendo quatro concentrações de $\mathrm{Mn}^{2+}$ mostrou, pelo teste $F$, efeitos significativos, ao nível de $5 \%$, de concentrações de $\mathrm{Mn}^{2+}$, genótipos e interação genótipos $x$ concentração de manganês - Quadro 2.

O quadro 3 apresenta o comprimento médio das raízes dos 25 genótipos de trigo medidos após doze dias de crescimento em soluções contendo quatro diferentes concentrações de manganês.

Considerando as médias dos genótipos estudados em solução contendo $0,11 \mathrm{mg} /$ litro de manganês, verifica-se que 0 ' $\mathrm{BH}-1146$ ' mostrou as rázes mais compridas. Esse resultado confirma o potencial genético no crescimento rápido das rázes apresentado por esse cultivar no experimento citado. 


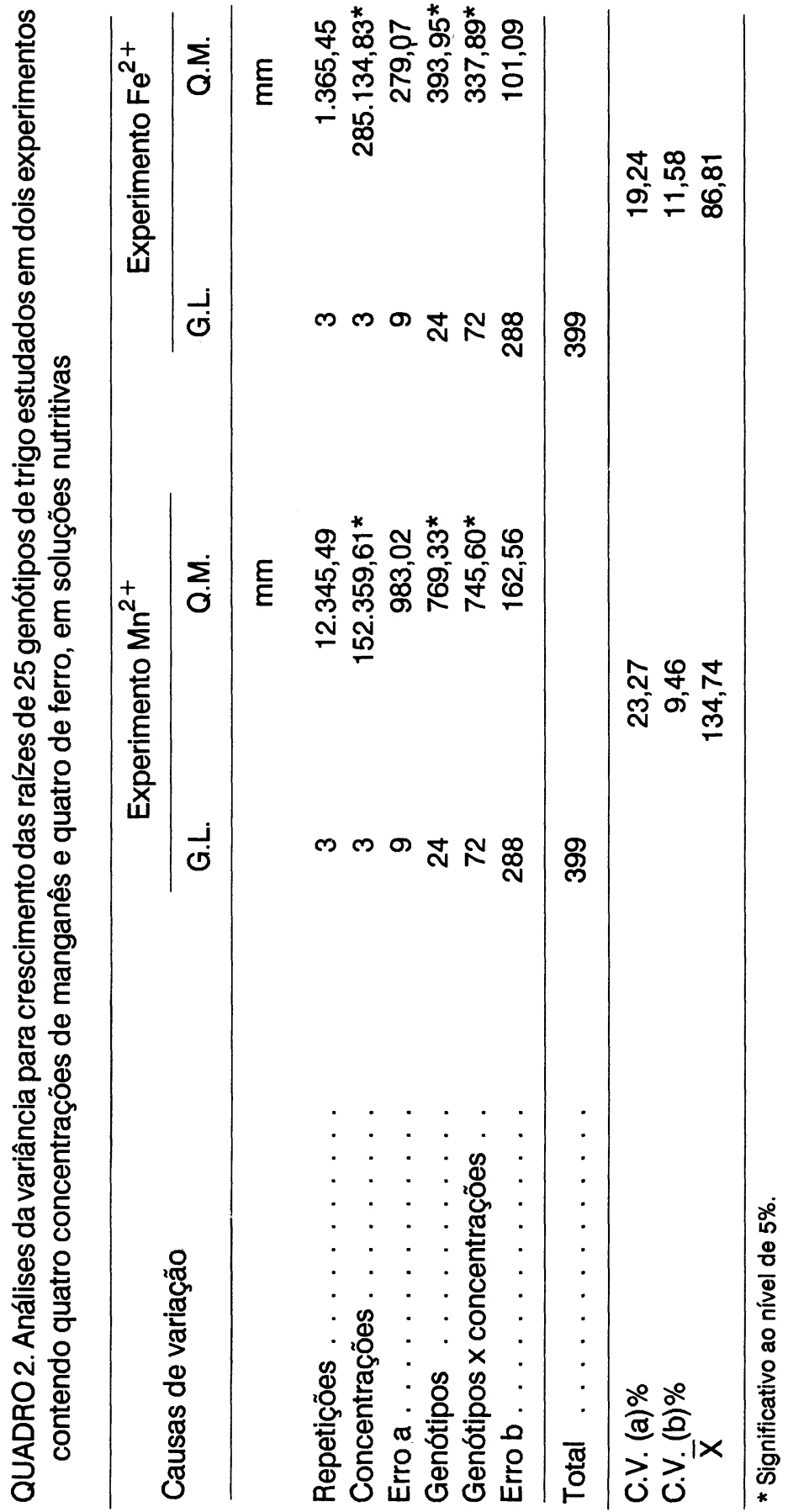




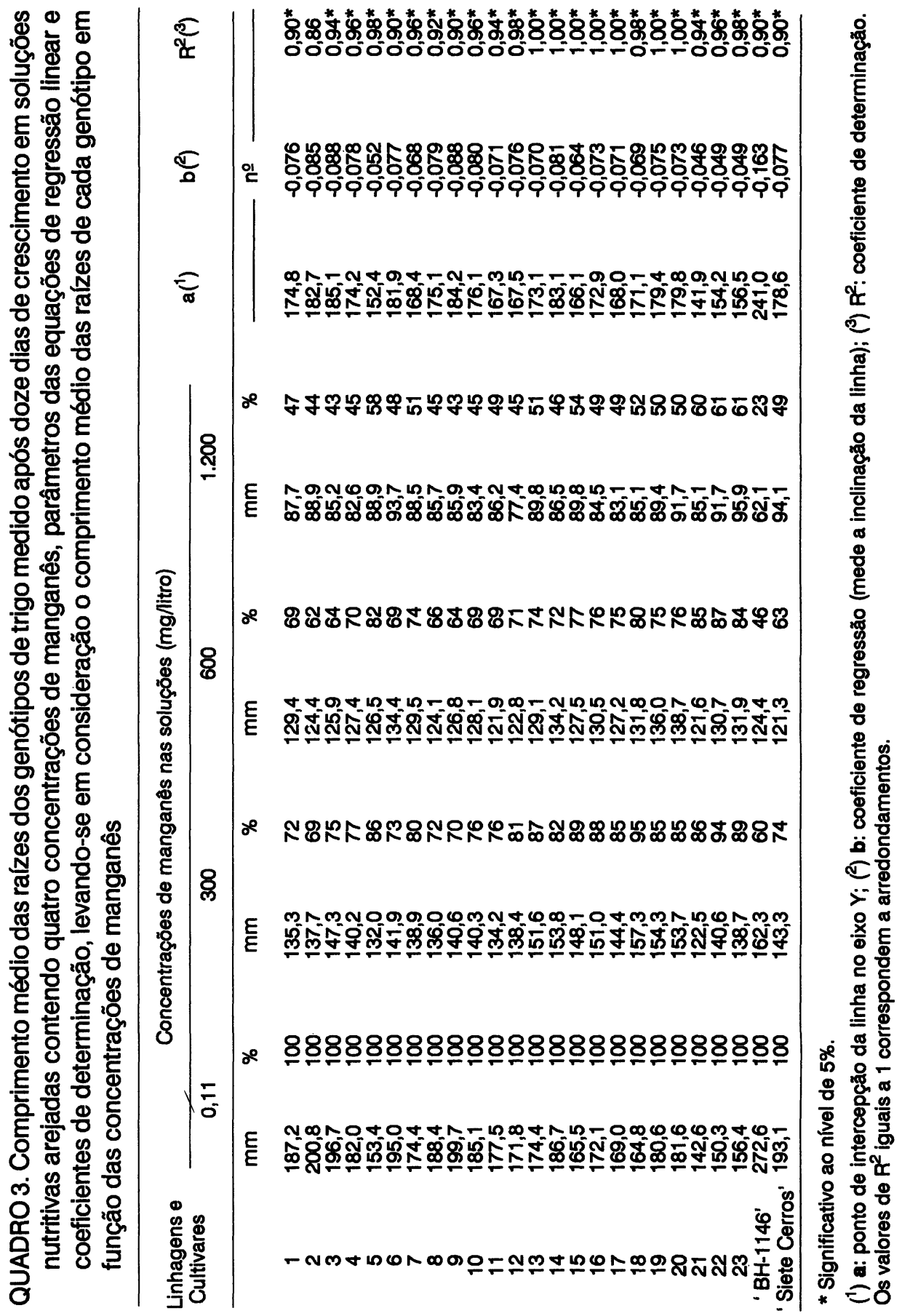


Estudando o comportamento de cada genótipo nas diferentes concentrações de manganês, observa-se que, à medida que essas concentrações aumentaram, houve redução no crescimento das ralzes de todos os genótipos.

Os resultados confirmaram ser o ' $\mathrm{BH}-1146$ ' muito sensível à toxicidade de manganês. No ensaio considerado, houve uma redução de $77 \%$ no crescimento das suas rafzes à medida que se aumentaram as concentrações de manganês de 0,11 para $1.200 \mathrm{mg} /$ litro. Os demais genótipos foram considerados tolerantes, por mostrar reduções do sistema radicular, de 39 a $57 \%$, à medida que se elevaram as concentrações de manganês de 0,11 para $1.200 \mathrm{mg} /$ litro. Por outro lado, as linhagens 5, 21, 22 e 23 apresentaram-se como muito tolerantes em relação ao 'Siete Cerros', utilizado como controle, com reduções de 39 a $42 \%$ no comprimento das raízes, nas mesmas condições. Esses genótipos foram considerados fontes genéticas de alto valor para um programa de melhoramento onde a tolerância à toxicidade de manganês for desejada.

O quadro 3 também apresenta os parâmetros das equações de regressão linear e os coeficientes de determinação, levando-se em consideração o comprimento médio das raízes de cada genótipo em função das quatro concentrações de $\mathrm{Mn}^{2+}$ : o coeficiente de regressão (b) para o cultivar Siete Cerros (tolerante à toxicidade de $\mathrm{Mn}^{2+}$ ) foi de $-0,077$ e para o ' $\mathrm{BH}-1146$ ' (sensivel à toxicidade de $\mathrm{Mn}^{2+}$ ), -0,163. As 23 linhagens avaliadas apresentaram coeficientes de regressão variáveis de $-0,046$ a -0,088, que, em comparação com o do 'BH-1146,' evidencia o elevado grau de tolerância que foi transferido por cruzamento do cultivar Siete Cerros para essas linhagens.

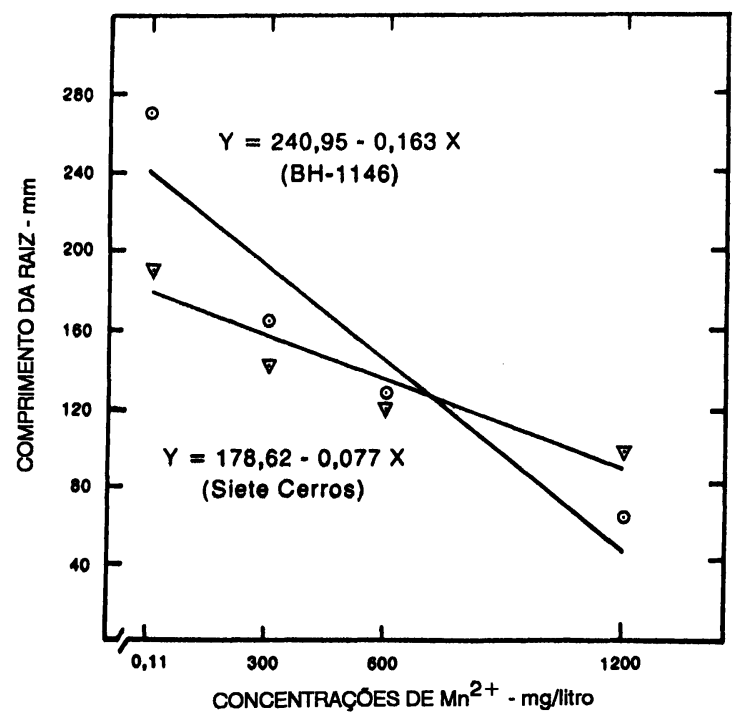

Figura 1. Respostas lineares dos comprimentos das raízes dos cultivares de trigo Siete Cerros e $\mathrm{BH}-1146$, após doze dias de crescimento em soluçóes nutritivas arejadas contendo quatro concentrações de $\mathrm{Mn}^{2+}$. 
Os coeficientes de determinação $\left(\mathrm{R}^{2}\right)$ nas análises de correlação entre o comprimento das raízes e as concentrações de manganês mostram elevado grau de associação negativa entre essas variáveis.

As equações de regressão linear dos cultivares BH-1146 e Siete Cerros, representadas na figura 1, mostram, para o 'BH-1146', maior inclinação da linha, confirmando sua maior sensibilidade às concentrações de manganês.

A análise da variância para crescimento das ralzes de 25 genótipos de trigo estudados no experimento contendo quatro concentrações de $\mathrm{Fe}^{2+}$ mostrou, pelo teste $F$, efeitos significativos, ao nível de $5 \%$, de concentrações de $\mathrm{Fe}^{2+}$, genótipos e interação genótipos $x$ concentrações de ferro, conforme quadro 2.

Os comprimentos médios das raízes dos 25 genótipos de trigo, medidos após doze dias de crescimento em soluções contendo quatro diferentes concentrações de ferro, acham-se no quadro 4.

Considerando-se as médias dos diferentes genótipos em solução contendo $0,56 \mathrm{mg} /$ /itro de ferro, verifica-se que o ' $\mathrm{BH}-1146$ ' mostrou as raizes mais compridas, confirmando o seu potencial genético no crescimento das rafzes, já discutido nos ensaios anteriores.

Estudando o comportamento de cada genótipo nas diferentes concentrações de ferro, verifica-se que, à medida que essas concentrações foram aumentadas, houve reduções no crescimento das raízes de todos os genótipos.

No ensaio considerado, o 'BH-1146' foi muito sensível à toxicidade de ferro, com uma redução de $76 \%$ no crescimento de suas rázes à medida que se aumentou a concentração de ferro de 0,56 para $10 \mathrm{mg} /$ itro. Os demais genótipos tiveram reduções do sistema radicular de 44 a $60 \%$, nas mesmas condições, sendo considerados tolerantes à toxicidade de ferro. $O$ cultivar Siete Cerros e as linhagens $3,8,11,15$ e 17 apresentaram-se como muito tolerantes, com reduções de 44 a $50 \%$ no comprimento das raízes nas mesmas condições. Esses genótipos se destacaram como fontes genéticas para tolerância à toxicidade de ferro, para um programa de melhoramento de trigo.

Os parâmetros das equações de regressão linear e os coeficientes de correlação, levando-se em consideração o comprimento médio das ralzes de cada genótipo em função das quatro concentrações de $\mathrm{Fe}^{2+}$, acham-se no quadro 4.

$O$ coeficiente de regressão (b) para 'Siete Cerros' (tolerante à toxicidade de $\mathrm{Fe}^{2+}$ ) foi de $-4,60$ e para $\mathrm{O}$ ' $\mathrm{BH}-1146$ ' (sensivel à toxicidade de $\mathrm{Fe}^{2+}$ ), de $-8,30$. As 23 linhagens estudadas mostraram coeficientes de regressão variando de $-5,08$ a $-6,83$ que, em comparação com o coeficiente apresentado pelo 'BH-1146', evidencia maior grau de tolerância, que foi transferido do 'Siete Cerros', por meio de cruzamento, para essas linhagens.

As equações de regressão linear dos cultivares BH-1146 e Siete Cerros, representadas na figura 2, revelam, para o 'Siete Cerros', menor inclinação da linha, confirmando sua maior tolerância às concentrações crescentes de ferro nas soluções nutritivas. 


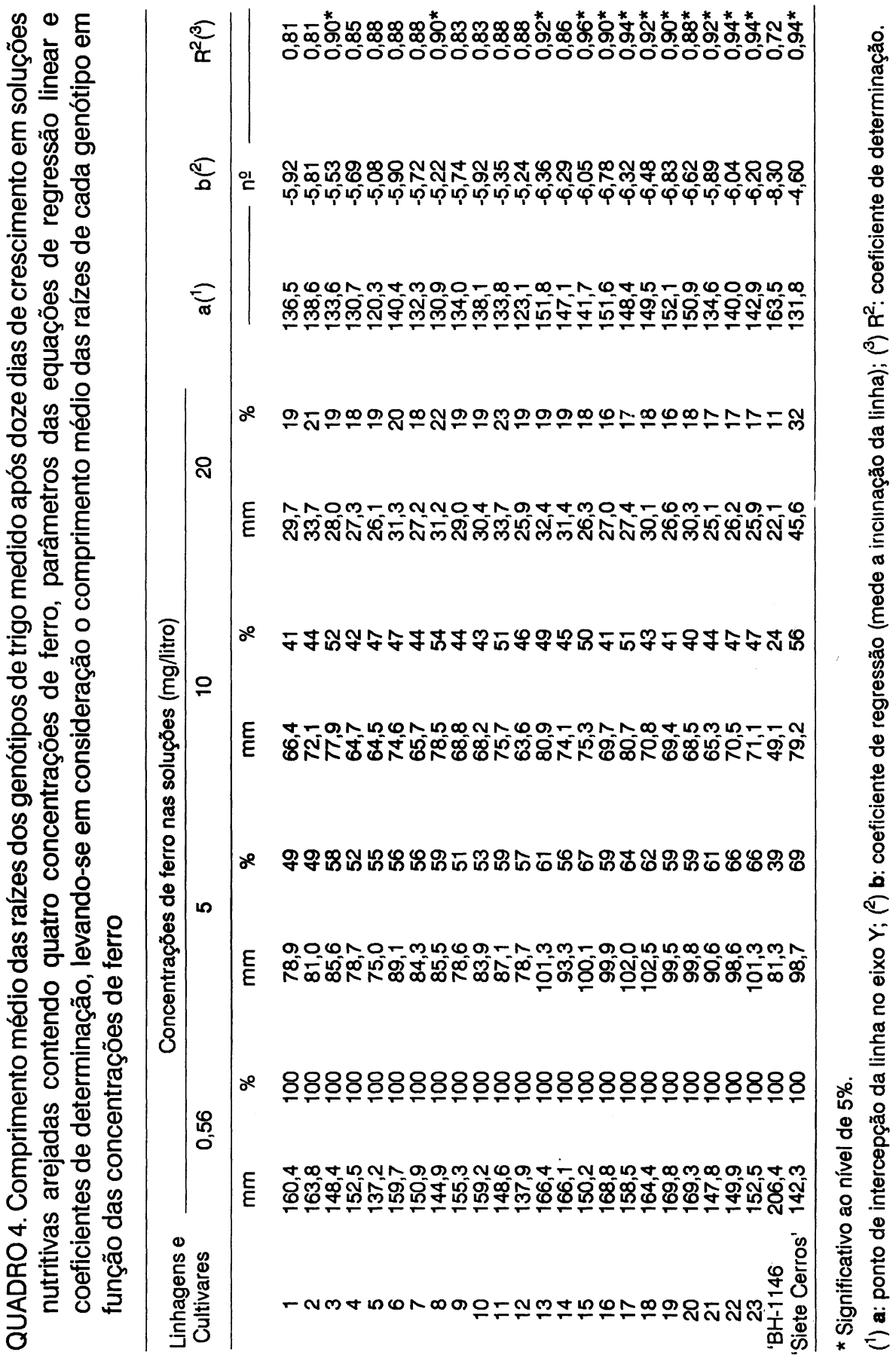




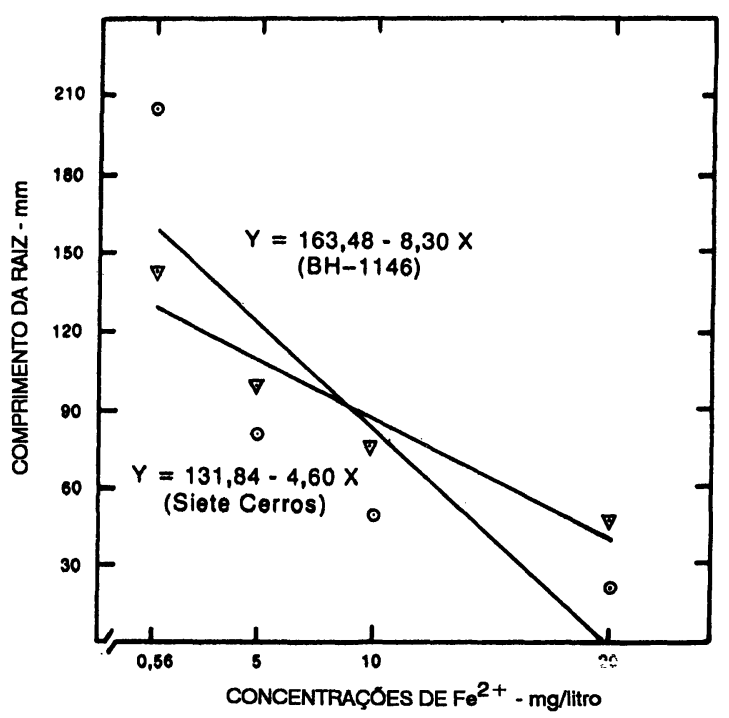

FIGURA 2. Respostas lineares dos comprimentos das raízes dos cultivares de trigo Siete Cerros e $\mathrm{BH}-1146$, após doze dias de crescimento em soluçóes nutritivas arejadas contendo quatro concentraçठ̇es de $\mathrm{Fe}^{2+}$.

Apesar de os coeficientes de determinação entre o comprimento das ralzes e as concentrações de ferro serem significativos ao nivel de $5 \%$ somente para as linhagens $3,8,13,15,16,17,18,19,21,22$ e 23 e para o 'Siete Cerros', em razão do pequeno número de observações, as demais exibiram valores elevados, mostrando grande associação negativa entre as duas variáveis avaliadas.

As 23 linhagens selecionadas a partir do cruzamento $\mathrm{BH}-1146 \times$ Siete Cerros confirmaram sua tolerância à toxicidade de alumínio, manganês e ferro. Esses genótipos deverão ser avaliados em condições de solo ácido para verificar quais teriam qualidades, como alta produção de grãos e resistência às doenças, para serem multiplicados e recomendados aos agricultores.

\section{CONCLUSÕES}

1. Os resultados mostram que os genes encontrados no cultivar $\mathrm{BH}-1146$, de porte alto, para tolerância ao alumínio, e aqueles do cultivar Siete Cerros, de porte semi-anão, condicionando tolerância à toxicidade de manganês e ferro, apresentaram comportamento independente, permitindo, a partir do seu cruzamento, a obtenção de linhagens de porte alto ou semi-anão, com tolerância simultânea aos três tipos de toxicidade considerados.

2. As linhagens obtidas representam germoplasmas valiosos como fontes genéticas de tolerância à toxicidade de alumínio, ferro e manganês, visando à obtenção, por meio de cruzamentos, de cultivares para as regiões de solos ácidos, que representam a maioria da triticultura brasileira. 


\section{REFERÊNCIAS BIBLIOGRÁFICAS}

ANDREW, C.S. \& PIETERS, W.H.J. Manganese toxicity symptons of one temperate and seven tropical pasture legumes. Technical Paper Division of Tropical Pastures, Camberra, 4:2-8, 1970.

CAMARGO, C.E.O. de. Melhoramento do trigo: I. Hereditariedade da tolerância à toxicidade do alumínio. Bragantia, Campinas, 40:33-45, 1981.

_- Melhoramento do trigo: III. Evidência de controle genético na tolerância ao manganês e alumínio tóxico em trigo. Bragantia, Campinas, 42:91-103, 1983.

- Melhoramento do trigo: VI. Hereditariedade da tolerância a três concentrações de alumínio em soluçăo nutritiva. Bragantia, Campinas, 43(2):279-291, 1984.

- Melhoramento do trigo: XI. Estudo genético da tolerância à toxicidade de ferro. Bragantia, Campinas, 44(1):87-96, 1985.

- Tolerance of wheat cultivars and evidence of genetic control to different levels of manganese in nutrient solution. In: INTERNATIONAL SYMPOSIUM ON MANGANESE IN SOILS AND PLANTS, Adelaide, 1988. Contributed papers. Adelaide, University of Adelaide - Waite Agricultural Research Institute, 1988. p.109-112.

—; FELICIO, J.C.; FREITAS, J.G. de \& FERREIRA FILHO, A.W.P. Tolerância de trigo, triticale e centeio a diferentes níveis de ferro em solução nutritiva. Bragantia, Campinas, 47(2):295-304, 1988.

\& FREITAS, J.G. de. Tolerância de cultivares de trigo a diferentes níveis de ferro em solução nutritiva. Bragantia, Campinas, 44(1):65-75, 1985.

- - \& FERREIRA FILHO, A.W.P. Efeito de diferentes doses de Fe em solução nutritiva no desenvolvimento da raiz primária de trigo. Pesquisa Agropecuária Brasileira, Brasília, 24(12):1529-1535, 1989.

; KRONSTAD, W.E. \& METZGER, R.J. Parent-progeny regression estimates and associations of height level with aluminum toxicity and grain yield in wheat. Crop Sclence, Madison, 20(3):355-358, 1980.

\& OLIVEIRA, O.F. de. Tolerância de cultivares de trigo a diferentes níveis de alumínio em solução nutritiva e no solo. Bragantia, Campinas, 40:21-31, 1981.

\& —_. Tolerância de cultivares de trigo a diferentes níveis de manganês em solução nutritiva. Bragantia, Campinas, 42:65-78, 1983.

FOY, C.D. General principles involved in screening plants for aluminum and manganese tolerance. In: WORKSHOP ON PLANT ADAPTATION TO MINERAL STRESS IN PROBLEM SOILS, Beltsville, 1976. Proceedings. Ithaca, Cornell University, 1976. p.255-267.

; CHANEY, R.L. \& WHITE, M.C. The physiology of metal toxicity in plants. Annual Review of Plant Physiology, Palo Alto, 29:511-566, 1978.

-; FLEMING, A.L. \& SCHWARTZ, J.W. Opposite aluminum and manganese tolerances of two wheat varieties. Agronomy Journal, Madison, 65(1):123-126, 1973.

LAGOS, M.B.; FERNANDES, M.I.B.M.; CARVALHO, F.I.F. \& CAMARGO, C.E. de O. Locallzação do gene(s) de tolerância ao crestamento em trigo cv. BH-1146 (Triticum aestivum L.). s.l., s.ed., 1984. 1p. Trabalho apresentado na 13a Reunião Nacional de Pesquisa de Trigo, Cruz Alta, 1984.

MOORE, D.P.; KRONSTAD, W.E. \& METZGER, R.J. Screening wheat for aluminum tolerance. In: WORKSHOP ON PLANT ADAPTATION TO MINERAL STRESS IN PROBLEM SOILS, BeltSville, 1976. Proceedings. Ithaca, Cornell University, 1976. p.287-295.

STEEL, R.G.D. \& TORRIE, J.H. Principles and procedures of statistics. New York, McGraw-Hill, 1960. 481p. 